\title{
Levelling and Rule Restructuring in Old English Adjectives
}

\author{
Don Ringe* \\ University of Pennsylvania, Philadelphia, PA, USA \\ dringe@sas.upenn.edu
}

\begin{abstract}
The distribution of short low vowels in West Saxon Old English adjectives cannot be explained entirely by levelling of surface forms and does not reflect lengthening in open syllables. A combination of levelling and rule restructuring is needed to account for the observed pattern.
\end{abstract}

\section{Keywords}

Old English - adjectives - alternations - levelling - rule restructuring

Sound changes early in the prehistory of Old English (OE) gave rise to an alternation between short low vowels both between and within paradigms: $a$ (probably /a/) occurred before a single or geminate consonant which was followed by a back vowel, while $\propto$ (almost certainly /æ/) normally occurred elsewhere (Campbell 1962: 52-53, 6o-62, Hogg 2011: 78-81, 93-96, Ringe and Taylor 2014: $146-149,189-196) .{ }^{1}$ In the majority paradigm of masculine and

* I am grateful to Ronald Kim, Patrick Stiles, and two anonymous reviewers for helpful comments on earlier versions of this paper. The opinions expressed are my own, as are all errors and infelicities.

1 The environments in which $a$ appeared may originally have been slightly more extensive, but the data are messy; see Campbell 1962: 61 and Hogg 2011: 94 for discussion. The difference

(C) DON RINGE, 2015 | DOI: 10.1163/22125892-00301001

This is an open access article distributed under the terms of the Creative Commons

Attribution-Noncommercial 3.o Unported (CC-BY-NC 3.0) License. 
neuter nouns, traditionally called " $a$-stems", that distribution remains largely undisturbed, probably because it coincided with the morphological opposition between singular and plural forms. For instance, stcef 'stick, staff' exhibits gen. sg. stcefes and dat. sg. stcefe, with expected $\propto$ before endings beginning with $e$, while nom.-acc. pl. stafas, gen. pl. stafa, and dat. pl. stafum show expected $a$ before endings beginning with back vowels. In most other paradigms, though, $a$ has spread at the expense of $a$. For instance, though the feminine noun pracu 'power, force' and its compounds continue to exhibit a non-nominative singular form ${ }^{2}$ prece, apparently because the noun is poetic and the alternation was preserved in traditional formulas (Ringe and Taylor 2014: 195), $a$ appears instead of $a$ in the oblique singular of most similar feminine nouns; we find faru, fare 'journey', lacu, lace 'stream, pool', talu, tale 'number, series, narrative', and so on.

In strong adjectives of this shape in the West Saxon (ws) dialect, however, $a$ has not spread through the entire paradigm: it appears in all open syllables regardless of whether the following vowel is back or front, but not in closed syllables. For instance, the usual ws paradigm of hwcet 'sharp, quick, bold' is the following (cf. Campbell 1962: 263-264, Hogg 1996: 6o, Hogg and Fulk 2011: 154-155); note that the oblique singular forms are identical for the masculine and neuter, and the oblique plural forms are identical for all three genders.

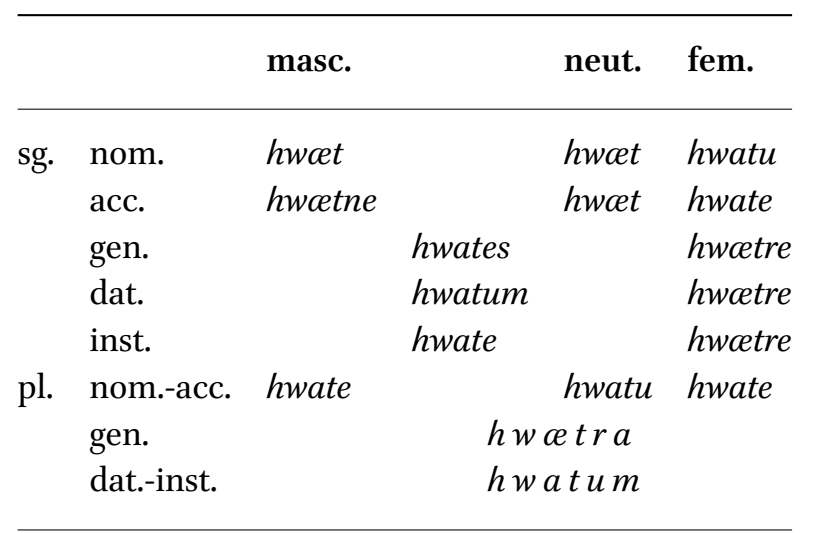

between $a$ and $\alpha$ became a phonemic contrast surprisingly early in the prehistory of oE; see Ringe and Taylor 2014: 196-199.

2 By chance all the singular non-nominative case endings of the majority feminine paradigm, traditionally called “ $\bar{o}$-stems", merged in -e. 
It can be seen that the four forms ending in -e or -es-namely, the fem. acc. sg., the masc./neut. gen. sg., the masc./neut. inst. sg., and the masc./fem. nom.-acc. pl. - exhibit $a$ rather than $a$ in the root syllable; so do adverbs in -e derived from adjectives of this type. ws adjectives with $a$ in the root (about ten altogether) normally exhibit this pattern.

In early ws there is very little variation in the pattern; $c$ appears occasionally before $-e$, but $a$ is overwhelmingly the norm. From the Cura Pastoralis Cosijn gives hrade $4 \times$ vs. hrcede $1 \times$, late $2 \times$, ware $1 \times$, and strcece $1 \times$ (Cosijn 1886: 58 ), with adverbs hraðe $8 \times$, raðe $2 \times$ (plus an unspecified number of times in Orosius, but no ${ }^{*}$ rceðe), late $3 \times$, rade $1 \times$, and in the Parker Chronicle oftrade $1 \times$ (Cosijn 1883: 2); from the latter text Sprockel adds hwate and ware $1 \times$ each and the adverbs rape and forhrape $2 \times$ each, late $1 \times$, with no forms exhibiting $a$ (Sprockel 1965: 8, 191): altogether 29+ forms with $a$ but only two with $a$. The forms with $a$ could be Mercianisms, since obvious Mercian spellings (such as onwald for anweald 'authority') appear in early ws texts and since the Anglian dialects normally exhibit front vowels in these forms (see further below).

Late ws texts exhibit more variation. Perusal of the Dictionary of Old English Corpus yields the following relevant late ws forms of typical strong adjectives and adverbs of this class: ${ }^{3}$

ber 'bare':

bare $1 \times$

glced 'glad':

glade $4 \times,-$ es $1 \times$

vs. glcede $9 \times$

hrced, hrce 'quick':

hwcet 'sharp':

hwate $8 \times$

vs. hrcede $14 \times,-\partial-37 \times$

leet 'slow':

late $63 \times$

vs. hwcete $2 \times$

smcel 'narrow':

smale $70 \times$, -es $2 \times$

vs. laete $4 \times$

strcec 'stern':

vs. smcele $19 \times$

strcece $1 \times$

weer 'aware':

ware $5^{\times}$

vs. wcere at least $14 \times,{ }^{4}$ gewcere $1 \times$

3 I omit blace 'black' because forms with $a$ are difficult to distinguish from forms of $b l \bar{a} c$ 'shining'; I omit sced 'sated' because of the labor of distinguishing its forms in - $e$ from the more than 1,90o examples of late ws sce्de 'said'. (There is one example of sade, but none of the gen. sg. *sades; the adjective is rare.) The numbers are of course approximations; I have tried to weed out homonymous forms of other lexemes and weak nom.(-acc.) sg. forms, but it is likely that I have missed a few examples.

4 I extracted these from among the more than 3,000 examples of wëre 'were' by searching for the collocation of the form with bèon and $b \bar{e} o ð$; it is unlikely that I found all relevant examples. 
It can be seen that forms with $a$ predominate when the number of examples is large, but that is because a majority of the examples of hraðe, late, and smale are adverbs and there is less variation among the adverbs. In purely descriptive terms we find $a$ for expected $c$ in these forms overwhelmingly among adverbs both in early and in late ws, but among adjectives only in early ws; late ws adjectives exhibit considerable variation between $a$ and $c e$.

It is possible that the divergent pattern of late ws adjectives reflects a difference in the dialectal basis of written early and late ws. However, a more economical account would ascribe the variation to the speech habits of non-ws scribes (see the discussions of Campbell 1962: 8-9 and Brunner 1965: 4-5 with references). This is plausible not only because late ws was a semi-standardized "chancery language", written by speakers of all dialects of English, but also, in this particular case, because non-ws dialects had front vowels in the corresponding adjective and adverb forms (Campbell 1962: 264). The numbers are necessarily small, even in the larger non-ws glosses, but the pattern is consistent. From the Vespasian Psalter glosses we have nom. pl. and $(3 \times)$ adv. hreðe and acc. pl. strece, all with $e<{ }^{*} æ$ by the Mercian "second fronting"; from the Lindisfarne Gospels glosses we have glced $(d) e(3 \times)$, gewcere, and the adverb (h)reðe $(10 \times)$ varying with hraðe $(7 \times)$, the latter possibly by levelling from cptv. hraður. Thus the handbooks are probably correct to maintain that the pattern of alternation exemplified in the adjective paradigm given above is the native ws pattern.

Back $a$ rather than front $\alpha$ in adverbs in - $e$ could conceivably have been levelled in from the comparatives and superlatives in -or and -ost, yielding a paradigm without alternation (like the feminine nouns faru, etc., cited above). ${ }^{5}$ Levelling is also usually invoked to account for the spread of $a$ in strong adjectives (cf. e.g. Wright and Wright 1925: 39). But levelling of surface forms offers no explanation for the fact that only open syllables are affected by the change (so Hogg and Fulk 2011: 155); that must be the result of a different mechanism of change.

5 Levelling from the marked forms into the unmarked form would be mildly surprising, but it is not impossible; in spite of hopeful hypotheses to the contrary, levelling occurs in all directions. A relevant example is Goth. alpeis 'old', evidently based on comparative alpiza (cf. oN ellri) and replacing the reflex of PGmc. *aldaz ( о e eald, oHG alt), which must be inherited because it is cognate with Lat. altus 'tall, high, deep'. For the Verner's Law alternation in this paradigm cf. PGmc. *jungaz 'young' (Goth. juggs, on ungr, etc.): *junhizan- 'younger' (Goth. jūhiza, on œri). 
The only researcher who has offered an alternative explanation for this pattern is Richard Hogg. Hogg 1996: 61-63 discusses earlier treatments and demonstrates that none of his predecessors has offered a convincing explanation for the fact that $a$ appears to have spread only part of the way through the paradigms of these adjectives, and that the limits of its spread can be defined phonologically. He then proposes that /a/ was actually longer than /æ/ in ws OE — in effect, half-long [a.] — and that ws spellings like hwate reflect the earliest stage of vowel lengthening in open syllables in English (Hogg 1996: 63-69). There are several reasons why Hogg's proposal should be rejected, as follows.

There is no actual evidence that the spelling $a$ for expected $a$ in ws OE represents any degree of vowel lengthening. In particular, this supposedly lengthened vowel did not merge with oE long $\bar{a}$. We know that no merger occurred because long $\bar{a}$ was rounded south of the Thames some time in the 12th century, and the rounded pronunciation spread northward to (roughly) the Humber over the next century or so (Luick 1914-1940: 358-361); but the OE short low vowels, including unexpected $a$ in open syllables, were not rounded in that sound change. That is why Hogg must maintain that unexpected $a$ was half-long; and since it continued to function as a member of the set of short vowels, the half-length must have been subphonemic.

The contention that oE scribes consistently wrote a subphonemic vowel alternant in this one case, BUT NOT IN ANY OTHERS, is highly problematic; Hogg adduces no parallels, and I cannot think of any. Note especially that the OE short diphthongs $e a$ and $e o$ are not subphonemic variants, nor is the vowel variably written $a \sim o$, because lexemes with metathesis of $r$ demonstrate that those were contrastive units; that is, earn 'eagle' (without metathesis) contrasts both with $æ r n$ 'building' and with arn orn 'ran' (both with metathesis), and the stressed vowel of berstan 'to burst' (with metathesis) constrasts with that of beorht 'bright' (without metathesis). ${ }^{6}$

Though nonhigh short vowels were eventually lengthened in stressed open syllables in disyllabic words in English, that regular sound change becomes discernible only in the 12th century-more than two and a half centuries after

6 On $r$-metathesis see especially Stanley 1952. On the oE short diphthongs see e.g. Kuhn and Quirk 1953 with references, Campbell 1962: 107-108 with references, and especially Hogg 2011: 16-24 with references. The variation between $a$ and $o$ before nasals appears to be free, but that is almost certainly a mirage. It is more likely that the scribes were trying to write a contrastive unit (see the text above) for which they had no appropriate symbol, and likelier still that dialect mixture is involved; for comprehensive discussion see Toon 1983: 90-114. 
the ws low vowel phenomenon is solidly attested. If there is any connection between Hogg's half-lengthening and the later, well-attested change, the halflong vowel must have persisted as a stable subphonemic alternant for eight or ten generations, during which the $\mathrm{OE}$ system of low vowels was extensively restructured (see Luick 1914-1940: 341-364). Hogg adduces no parallels for such an improbable scenario; neither can I. Still worse, the 12th-century lengthening in question seems to have begun in northern England and spread southwards during the 13th century (see Luick 1914-1940: 397-409 for comprehensive discussion). It is difficult to see how it could be the continuation of a ws- that is, a SOUTHWESTERN-sound change. This pattern of philological evidence argues strongly that Hogg's half-lengthening, if real, has nothing to do with the much later northern Middle English lengthening.

But the strongest argument against Hogg's hypothesis is that there are numerous examples of OE $a$ and $e$ that it cannot account for without special pleading. I will discuss the classes of counterexamples in turn.

Most obviously, why do we find such gen. sg. and dat. sg. forms of nouns as dceges, dcege 'day', stcefes, stcefe 'staff', hwceles, hwcele 'whale', bøeces, brece 'back', feetes, feete 'container', etc., with $a$ in open syllables, if $a$ had been lengthened to $a$ in that position by a regular sound change? Forms with $a$ do occur, but they are comparatively rare until the latest period of our documents, when it seems clear that $a$ and $a$ had undergone a phonemic merger (Luick 19141940: 346-352). The forms deeges and deege are so common-more than 700 and more than 3,000 tokens respectively - that the tiny handful of competing forms with $a$ can easily be scribal errors. Hogg's suggestion that these $e$ in open syllables are purely graphic, concealing "real" $a$ (Hogg 1996: 67), again posits a type of behavior on the part of oE scribes that is unparalleled elsewhere in the tradition. Of course "morphological" spellings, in which a given morpheme is always spelled the same way in spite of alternations in its pronunciation, are common enough that positing them for $\mathrm{OE}$ would not be problematic; failure to note word-final obstruent devoicing (in Dutch, German, Polish, Russian, etc.) is a typical example. But that is not what Hogg is suggesting. He argues that, though $[æ]$ was lengthened to half-long $[a \cdot]$ in open syllables by regular sound change, scribes declined to write the new allophone as $\langle a\rangle$ in the singular forms of masculine and neuter a-stem nouns because that would have run counter to the salient distinction between singular and plural. But that distinction was already marked unambiguously by the number-and-case endings; thus scribes should have had no incentive to write $c$ for half-long [a.] in the singular forms.

A handful of feminine abstract nouns might pose a further problem for Hogg's analysis. Though in most cases $a$ has spread through the paradigm from 


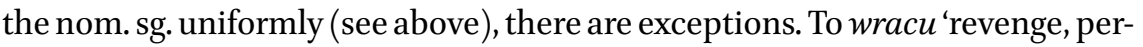
secution' we find oblique sg. wrace and wrcece; to sacu 'conflict, accusation' we find both sace and scece; to swapu 'track' we find both swape and swcepe. ${ }^{7} \mathrm{Cru}-$ cially, these paradigms contain no endingless forms in which "unlengthened" $\propto e$ could have survived, as it did in dee 'day', feet 'container', etc.; thus there was no reason at all for scribes to write $e$ if they were really pronouncing longer $a$. Unless all the forms with $c$ are really non-ws (see above), this pattern of variation is inconsistent with Hogg's lengthening hypothesis.

Still more instructive is a noun of this class in which *æ was diphthongized by an initial palatal consonant in ws. If the inherited paradigm had not been disturbed, we should find nom. sg. caru 'care, worry', oblique sg. ceare; in fact we find nom. sg. caru and cearu, oblique care and ceare. Only levelling can explain such an outcome. But if the variation in this paradigm is necessarily the result of levelling, economy of hypotheses should lead us to ascribe variation between $a$ and $a$ to levelling as well (if it is not the result of dialect mixture) - that is, to the extent that we can account for the resulting pattern by levelling.

Finally, though the spread of $a$ at the expense of $a$ can have been a comparatively recent change (from an early ws perspective) in most grammatical categories, in one class of forms it must be far older-and was not restricted to open syllables. Strong verbs of class vi inherited *a in the root, usually followed by a single consonant, in the present stem and the past participle; thus they ought to exhibit the usual alternation between $a$ and $c$. We expect to find, and do find, $a$ in infinitives such as faran 'to travel', present indicative pl. forms like farap, present participles like farende $\left(<{ }^{*}\right.$ farandī, with an original back vowel in the second syllable), and Anglian pres. indic. 1sg. forms like faru. On the other hand, the present subjunctive forms should be sg. *fære, pl. *ææren, the imperative sg. should be *fær, and the past participle should be feren; moreover, the pres. indic. 2sg. and 3 sg. should have been *færisi and * færipi, which by i-umlaut ought to have yielded ws *ferst and *ferp. None of the forms with $a$ occurs in $\mathrm{ws}^{8}$ before the latest period except past ptc. feeren, a rare variant in

7 Some care is necessary to distinguish the dat. sg. of these nouns from the homonymous forms of wree and swcep (both neut.). For instance, in the Cura Pastoralis wrece is clearly fem. $2 \times$ (beside wrace $5 \times$ ), clearly neut. $1 \times$, and ambiguous $2 \times$.

8 Southwest Mercian does exhibit an iptv. sg. fer which could reflect * fær by the Mercian second fronting, but could also reflect levelling of $e$ from the indic. 2sg. *feres (which happens to be unattested). Both the latter and 3sg. geondfereð could exhibit $e$ by i-umlaut of *æ, but their $e$ could also reflect * $æ$ by the second fronting, and that * $æ$ could be the i-umlaut of *a, exactly as in ws. For attestation of the forms see Kuhn 1965 . 
competition with faren. ${ }^{9}$ Otherwise we find subj. sg. fare, pl. faren, and iptv. sg. far (with levelled $a$ in a closed syllable); most importantly, the normal ws 2sg., 3sg. forms are fcerst, fcerp (Hedberg 1945: 242-243), reflecting *farisi and *faripi, with *a levelled in at the expense of * . The normal ws forms of other class VI strong verbs ${ }^{10}$ exhibit the same pattern. Thus *a must have spread through the paradigm of these verbs BEFORE i-umlaut occurred. But i-umlaut preceded regular syncope and apocope, which in turn preceded the shortening of long vowels in unstressed syllables (Ringe and Taylor 2014: 304 and passim). In other words, *a spread through the the paradigms of class VI strong verbs at a time when the language still distinguished long vowels from short vowels in all syllables, including unstressed syllables. That any stressed short vowel might have acquired subphonemic half-length in open syllables in such a vowel system is unlikely for typological reasons; levelling is much the more likely explanation (though why levelling should have occurred so early in these verbs remains an unanswered question). Once again, Occam's Razor urges a hypothesis of levelling for other, similar phenomena-in so far as levelling can explain the resulting pattern.

The problem is that levelling alone cannot explain the resulting pattern. ${ }^{11}$ We need a better solution to the problem of adjective forms like hwates, hwate, and in fact it is not difficult to construct one.

\section{3} The Key to the Problem: Rule Restructuring

Most OE adjectives had two full paradigms for use in different syntactic environments. In addition to the "strong" paradigm of hwcet, given above, there was a "weak" (n-stem) paradigm, whose inherited forms should have been the following; note that all forms but the nom. sg. and acc. sg. are identical for all three genders.

$9 \quad$ Moreover, fceren need not reflect prehistoric *færæn; it could reflect *farin, with levelled *a. See Campbell 1962: 306-307 for some less ambiguous examples.

10 Except j-presents such as hebban 'to lift', which exhibit an i-umlauted vowel (typically $e$ ) in all forms of the present stem.

11 So Hogg and Fulk 2011: 155, where the solution of Hogg 1996 is not advocated but not disavowed either. 


\begin{tabular}{|c|c|c|c|c|}
\hline & & masc. & neut. & fem. \\
\hline \multirow[t]{4}{*}{ sg. } & nom. & hwata & *hwæte & *hwæte \\
\hline & acc. & hwatan & *hwæte & hwatan \\
\hline & gen. & & $h w a t a n$ & \\
\hline & dat.-inst. & & hwatan & \\
\hline \multirow[t]{3}{*}{ pl. } & nom.-acc. & & hwatan & \\
\hline & gen. & & $h w a \tan a$ & \\
\hline & dat.-inst. & & hwatum & \\
\hline
\end{tabular}

(The oldest attestations of the disyllabic gen. pl. ending show that it was -ana; it later became -ena by the dissimilation of successive unstressed vowels. See e.g. Campbell 1962: 158-159, 249.) In this paradigm too we find hwate for expected *hwæte. However, in the weak paradigm $a$ already occurred in the root syllable in such an overwhelming majority of forms that replacement of *hwæte by hwate can be ascribed to paradigmatic levelling with complete confidence. ${ }^{12}$ The result was a paradigm with $a$ in the root in all forms regardless of the vowel in the ending. Crucially, it was also a paradigm in which THE ROOT SYLLABLE WAS ALWAYS OPEN.

Once levelling had occurred in the weak paradigm, the inherited rule governing the alternation of $a$ and $a$ no longer operated without exception in adjectives, since weak forms with the ending $-e$ exhibited $a$ in the root rather than $c$. It should then have been possible for native language learners - that is, children up to the age of about five or so-to abstract from the weak paradigm a rule that in adjectives (only) $a$, not $c$, occurred in root syllables if they were open, regardless of what vowel followed. Extension of that rule to the strong paradigm would give the attested ws distribution of vowels. I hypothesize that that is what happened.

It is true that the rule resulting from this reanalysis is "unnatural", but it is no more unnatural than the modern German umlaut rule. The latter has multiple morphological triggers, yet it operates on phonological units; it fronts back vowels, but shifts the back diphthong /av/ to /oy/ and leaves the halfback diphthongs /ar/and /oy/ untouched. Of course the German umlaut rule might be easier to learn than the ws oE adjective rule because the evidence

12 Readers who believe that a vowel should not have been levelled from non-nominative into nom. sg. forms should note that $a$ already occurred in the masc. nom. sg. 
for it is abundant and pervasive, but the oE rule should have been learnable too because of its simplicity. ${ }^{13}$

Reinterpretation of an existing rule on the part of native learners is a type of change which many researchers have suggested should be possible; see, for instance, Kiparsky 1982: 17-18, 60-61, 167-172, 190-191 for a range of examples. But phenomena that can be accounted for by rule reanalysis are often also amenable to explanation by surface-based "analogy". It is therefore important to identify examples which surface-based theories cannot handle. I think the pattern of $a$ and $a$ in ws oE strong adjectives is one; the productive rule changing $/ \mathrm{km} /, / \mathrm{k}^{\mathrm{h}} \mathrm{m} /$ to $[\mathrm{gm}]$ in the Attic dialect of Ancient Greek (Ringe and Eska 2013: 115-119) is another. The discovery of further examples that cannot be explained away would be welcome.

Thus the solution advocated here involves no historical changes of doubtful types and accounts for all the facts.

\section{References}

Brunner, Karl. 1965. Altenglische Grammatik. 3rd ed. Tübingen: Niemeyer.

Buckley, Eugene. 2000. On the naturalness of unnatural rules. Proceedings from the Second Workshop on American Indigenous Languages, Uсsв Working Papers in Linguistics 9.16-29.

Buckley, Eugene and Amanda Seidl. 2005. On the learning of arbitrary phonological rules. Language Learning and Development 1.289-316.

Campbell, A. 1962. Old English grammar. 2d ed. Oxford: Clarendon Press.

Cosijn, P.J. 1883. Altwestsächsische Grammatik. Erste Hälfte. The Hague: Nijhoff.

Cosijn, P.J. 1886. Altwestsächsische Grammatik. Zweite Hälfte: die Flexion. The Hague: Nijhoff.

Hedberg, Johannes. 1945. The syncope of the Old English present endings: a dialect criterion. Lund: Gleerup. (= Lund Studies in English XII.)

Hogg, Richard M. 1996. Old English open syllable lengthening. Transactions of the Philological Society 94: 57-72.

Hogg, Richard M. 2011. A grammar of Old English. Vol. 1: phonology. Paperback ed. Oxford: Wiley-Blackwell.

Hogg, Richard M. and Robert D. Fulk. 2011. A grammar of Old English. Vol. 2: morphology. Paperback ed. Oxford: Wiley-Blackwell.

13 On unnatural rules in general see Buckley 2000; on the learnability of unnatural rules see Buckley and Seidl 2005. 
Kiparsky, Paul. 1982. Explanation in phonology. Dordrecht: Foris.

Kuhn, Sherman M. (ed.). 1965. The Vespasian Psalter. Ann Arbor: U. of Michigan Press. Kuhn, Sherman M. and Randolph Quirk. 1953. Some recent interpretations of Old English digraph spellings. Language 29: 143-156.

Luick, Karl. 1914-1940. Historische Grammatik der englischen Sprache. Erster Band. Stuttgart: Tauchnitz.

Ringe, Don, and Joseph F. Eska. 2013. Historical linguistics: toward a twenty-first century reintegration. Cambridge: Cambridge U. Press.

Ringe, Don, and Ann Taylor. 2014. The development of Old English. A linguistic history of English, vol. 2. Oxford: Oxford U. Press.

Sprockel, C. 1965. The language of the Parker Chronicle. Vol. 1: phonology and accidence. The Hague: Nijhoff.

Stanley, E.G. 1952. The chronology of $r$-metathesis in Old English. English and Germanic Studies 5: 103-115.

Toon, Thomas. 1983. The politics of early Old English sound change. New York: Academic Press.

Wright, Joseph, and Elizabeth M. Wright. 1925. Old English grammar. 3rd ed. Oxford: Oxford U. Press. 